\title{
Translocation of PEGylated quantum dots across rat alveolar epithelial cell monolayers
}

\author{
This article was published in the following Dove Press journal: \\ International Journal of Nanomedicine \\ 9 November 2011 \\ Number of times this article has been viewed
}

\author{
Farnoosh Fazlollahi ${ }^{1,8}$ \\ Arnold Sipos ${ }^{1,2}$ \\ Yong Ho Kim ${ }^{1,2}$ \\ Sarah F Hamm-Alvarez ${ }^{6}$ \\ Zea Borok ${ }^{1-3}$ \\ Kwang-Jin Kim ${ }^{1,2,5-7}$ \\ Edward D Crandall 1,2,4,8 \\ 'Will Rogers Institute Pulmonary \\ Research Center, ${ }^{2}$ Department \\ of Medicine, ${ }^{3}$ Department \\ of Biochemistry and Molecular \\ Biology, ${ }^{4}$ Department of Pathology, \\ ${ }^{5}$ Department of Physiology \\ and Biophysics, ${ }^{6}$ Department \\ of Pharmacology and Pharmaceutical \\ Sciences, ${ }^{7}$ Department of Biomedical \\ Engineering, ${ }^{8}$ Mork Family Department \\ of Chemical Engineering and Materials \\ Science, University of Southern \\ California, Los Angeles, CA, USA
}

Correspondence: Edward D Crandall Department of Medicine, University of Southern California, 2020 Zonal Avenue, IRD 606, Los Angeles,

CA 90033, USA

Tel +I 3232267593

Fax +I 3232262899

Email ecrandal@usc.edu
Background: In this study, primary rat alveolar epithelial cell monolayers (RAECM) were used to investigate transalveolar epithelial quantum dot trafficking rates and underlying transport mechanisms.

Methods: Trafficking rates of quantum dots (PEGylated CdSe/ZnS, core size $5.3 \mathrm{~nm}$, hydrodynamic size $25 \mathrm{~nm}$ ) in the apical-to-basolateral direction across RAECM were determined. Changes in bioelectric properties (ie, transmonolayer resistance and equivalent active ion transport rate) of RAECM in the presence or absence of quantum dots were measured. Involvement of endocytic pathways in quantum dot trafficking across RAECM was assessed using specific inhibitors (eg, methyl- $\beta$-cyclodextrin, chlorpromazine, and dynasore for caveolin-, clathrin-, and dynamin-mediated endocytosis, respectively). The effects of lowering tight junctional resistance on quantum dot trafficking were determined by depleting $\mathrm{Ca}^{2+}$ in apical and basolateral bathing fluids of RAECM using $2 \mathrm{mM}$ EGTA. Effects of temperature on quantum dot trafficking were studied by lowering temperature from $37^{\circ} \mathrm{C}$ to $4^{\circ} \mathrm{C}$.

Results: Apical exposure of RAECM to quantum dots did not elicit changes in transmonolayer resistance or ion transport rate for up to 24 hours; quantum dot trafficking rates were not surface charge-dependent; methyl- $\beta$-cyclodextrin, chlorpromazine, and dynasore did not decrease quantum dot trafficking rates; lowering of temperature decreased transmonolayer resistance by approximately $90 \%$ with a concomitant increase in quantum dot trafficking by about $80 \%$; and 24 hours of treatment of RAECM with EGTA decreased transmonolayer resistance by about $95 \%$, with increased quantum dot trafficking of up to approximately $130 \%$.

Conclusion: These data indicate that quantum dots do not injure RAECM and that quantum dot trafficking does not appear to take place via endocytic pathways involving caveolin, clathrin, or dynamin. We conclude that quantum dot translocation across RAECM takes place via both transcellular and paracellular pathways and, based on comparison with our prior studies, interactions of nanoparticles with RAECM are strongly dependent on nanoparticle composition and surface properties.

Keywords: alveolar epithelial barrier, transport, paracellular pathways, endocytosis

\section{Introduction}

Nanoparticles (with at least one dimension $\leq 100 \mathrm{~nm}$ ) offer novel opportunities for biomedical applications, yet their mechanisms of interaction with biological cells, tissues, and organs (including the lung) have not been well defined. Recent reports have highlighted the need for systematic investigation of unknown, but potentially harmful, effects of nanomaterials in order to permit safer design and application in biomedicine. ${ }^{1-4}$ Ultrafine ambient particles (diameter $<100 \mathrm{~nm}$ ) overlap in size with engineered nanomaterials. Systematic studies of toxicity/trafficking of defined/ 
trackable engineered nanomaterials in the lung as a portal of entry to the systemic circulation and end organs would provide insight into the environmental health effects of air pollution and design of inhaled drug delivery systems.

Distal airspaces of the lung are lined with two types of alveolar epithelial cells, ie, type I (ATI) and type II (ATII) pneumocytes. ATI cells have thin cytoplasmic extensions $(<1 \mu \mathrm{m})$ that cover $90 \%$ of the internal surface area of the normal human lung and play an important role in gas exchange and alveolar fluid balance. ${ }^{5}$ ATII cells are involved in synthesis, secretion, and recycling of surfactant components and can transdifferentiate into ATI cells. ${ }^{6-8}$ However, due to the complex anatomy of the lung, specific mechanistic information regarding nanoparticle interactions with the lung is difficult to obtain from in vivo models. As an alternative approach, primary cultured rat ATII cells are known to undergo morphologic ${ }^{7}$ and phenotypic ${ }^{9}$ transition into ATI cell-like monolayers that can serve as a suitable in vitro model of the alveolar epithelial barrier for mechanistic investigations of transport and cell biology. Such rat alveolar epithelial cell monolayers (RAECM) exhibit relatively high transmonolayer resistance of about $2.5 \mathrm{k} \Omega \cdot \mathrm{cm}^{2}$ and well formed tight junctions, consistent with the expected properties of alveolar epithelium in vivo.

Semiconductor nanocrystals (eg, quantum dots) have improved optical properties compared with other fluorochromes and are used for biological imaging (both in vitro and in vivo $)^{10,11}$ and therapeutic applications (eg, drug delivery vectors ${ }^{12,13}$ and photosensitizers for phototherapy ${ }^{14,15}$ ). However, the core material of quantum dots (eg, cadmium) is toxic to cells and organisms, raising concerns regarding their suitability as biomarkers/labels. ${ }^{16,17}$ In addition, water dispersability, biocompatibility, chemical stability, and robust optical properties are required for the biological applications of quantum dots. ${ }^{18}$ Chemical coatings and/or surface layering are essential for meeting these requirements. These surface layers can prevent chemical degradation and/or leaching of toxic core materials, improving quantum dot cytocompatibility, and reducing their nonspecific binding. ${ }^{19}$ Numerous modifications of quantum dot surface chemistry have been explored, including functionalizable inorganic shells, such as silica ${ }^{20,21}$ or organic layer attachment, eg, polyethylene glycol (PEG) ${ }^{22}$ or bovine serum albumin. ${ }^{23}$ A surface modification using PEG is known to reduce cytotoxicity, and the amphiphilic properties of PEG result in enhanced solubility. Moreover, PEG modifications, ie, PEGylations, are well known to be biocompatible and nonimmunogenic, affording a long blood circulation time after intravenous injection by reducing opsonization via proteins and impeding uptake by macrophages in the reticuloendothelial system. ${ }^{24-29}$

It is currently thought that both the size and surface properties of nanoparticles affect the cytotoxicity and intracellular fate(s) of nanoparticles..$^{30-33}$ In this regard, we recently reported the trafficking properties of polystyrene nanoparticles with variable sizes and surface charges across RAECM. ${ }^{30,31}$ In brief, trafficking rates of polystyrene nanoparticles across RAECM are dependent on both surface charge density and size, in that we found an approximately 20-40 times greater flux for positively (versus negatively) charged polystyrene nanoparticles of similar size and that larger polystyrene nanoparticles (about $100 \mathrm{~nm}$ ) cross RAECM about 3-4 times slower than smaller polystyrene nanoparticles (20 nm) of similar surface charge. ${ }^{31}$ Polystyrene nanoparticles appear to be translocated across RAECM via nonendocytic transcellular pathways, possibly involving diffusion across the lipid bilayer of cell plasma membranes. ${ }^{30}$

In this study, we used PEGylated quantum dots with three surface modifications (amine-, carboxylate-, and nonmodified) with which to characterize nanoparticle uptake/ trafficking into/across RAECM. We found that these quantum dots do not affect the barrier properties of alveolar epithelium. They translocate across RAECM via both transcellular pathways (which appear to be independent of caveolin-, clathrin-, or dynamin-mediated endocytosis) and paracellular routes.

\section{Materials and methods RAECM}

The detailed procedure for preparation of RAECM has been described previously. ${ }^{34,35}$ This method involving the use of rats has been approved by the Institutional Animal Care and Use Committee of the University of Southern California. Briefly, ATII cells were freshly isolated from adult male, specific pathogen-free, Sprague-Dawley rats (125-150 g) using elastase digestion and enriched by IgG panning. ${ }^{34,35}$ Enriched ATII cells were plated onto tissue culture-treated polycarbonate filters (Transwell, $12 \mathrm{~mm}$ diameter, $0.4 \mu \mathrm{m}$ diameter pores, Corning-Costar, Cambridge, MA) at $1.2 \times 10^{6} \mathrm{cells} / \mathrm{cm}^{2}$. ATII cells were cultured in MDS (minimal defined serum-free medium with 10\% newborn bovine serum from Omega, Tarzana, CA). Minimal defined serum-free medium consists of a 1:1 mixture of Dulbecco's modified Eagle's medium and Ham's F-12 medium (Sigma, St Louis, MO) supplemented with $1 \mathrm{mM}$ nonessential amino acids (Sigma), $100 \mathrm{U} / \mathrm{mL}$ primocin (InvivoGen, San Diego, CA), 10 mM N-(2-hydroxyethyl) 
piperazine-N'-(2-ethanesulfonic acid) (Sigma), $1.25 \mathrm{mg} / \mathrm{mL}$ bovine serum albumin (BD Bioscience, San Jose, CA), and $2 \mathrm{mM}$ L-glutamine (Sigma). Cells were maintained at $37^{\circ} \mathrm{C}$ in a humidified atmosphere of $5 \% \mathrm{CO}_{2}$ and $95 \%$ air and fed every other day starting on day 3 in culture when confluent monolayers were formed. Transmonolayer resistance and potential difference were screened using a Millicell-ERS device (Millipore, Bedford, MA). The equivalent active ion transport rate was calculated as potential difference/transmonolayer resistance. We utilized RAECM at 4-7 days in culture with transmonolayer resistance $>2.5 \mathrm{k} \Omega \cdot \mathrm{cm}^{2}$ and a potential difference $>10 \mathrm{mV}$.

\section{Nanoparticles}

PEGylated quantum dots $(\mathrm{CdSe} / \mathrm{ZnS}$, core size $5.3 \mathrm{~nm}$, hydrodynamic size $25 \mathrm{~nm}$ ) which were non-modified, amine-modified, or carboxylate-modified, were purchased from eBioscience (San Diego, CA). Excitation/emission wavelengths were $360 / 610 \mathrm{~nm}$ for all quantum dots studied. Quantum dot zeta potential in water was determined using a Zetasizer (Malvern, Worcestershire, UK) with a measurement cell (with built-in electrodes) filled with $1 \mathrm{~mL}$ of various quantum dots suspended in water at $6.25 \mu \mathrm{g} / \mathrm{mL}$ by applying an electric field across the two electrodes.

\section{Quantum dot flux}

To measure rates of quantum dot translocation across RAECM, apical fluid was replaced at $\mathrm{t}=0$ with fresh culture medium containing various quantum dots at $6.25 \mu \mathrm{g} / \mathrm{mL}$. Apical-to-basolateral flux of quantum dots was estimated from quantum dots appearing in the basolateral fluid for up to 24 hours at $37^{\circ} \mathrm{C}$. Quantum dot concentrations in downstream fluid were estimated spectrofluorometrically using SpectraMax M2 (Molecular Devices, Sunnyvale, CA). Apical [quantum dot] was determined at $\mathrm{t}=0$ and at the end of flux experiments. [Quantum dot] of various samples was calculated using a standard curve generated with known concentrations of quantum dots in MDS. Flux $(J)$ was calculated as $J=(C V) / S / \Delta t$, where $C$ is [quantum dot] in basolateral fluid at time $\mathrm{t}=\Delta t, V$ is basolateral fluid volume ( $1.5 \mathrm{~mL}), S$ is nominal surface area of the monolayer $\left(1.13 \mathrm{~cm}^{2}\right)$ and $\Delta t$ is length of time for flux measurement (6 or 24 hours).

\section{Effects of decreased transmonolayer resistance}

In order to determine the effects of "leakier" tight junctions (increased tight junctional conductance) on trafficking rates of quantum dots across RAECM, quantum dot flux was measured in the presence of $2 \mathrm{mM}$ ethylene glycol-bis( $\beta$-aminoethyl ether) $\mathrm{N}, \mathrm{N}, \mathrm{N}^{\prime}, \mathrm{N}^{\prime}$-tetra-acetate (EGTA, Sigma) in both apical and basolateral fluids. RAECM were pretreated with EGTA for 30 minutes, followed by apical instillation of carboxylate-, amine-, or non-modified quantum dots at a final concentration of $6.25 \mu \mathrm{g} / \mathrm{mL}$ with continued presence of $2 \mathrm{mM}$ EGTA in both apical and basolateral fluids for 24 hours. Control monolayers were exposed apically to various quantum dots $(6.25 \mu \mathrm{g} / \mathrm{mL})$ in the absence of EGTA in the apical and basolateral fluids for 24 hours. Flux of quantum dots was assessed as described above. Bioelectric properties (ie, transmonolayer resistance, equivalent active ion transport rate, and potential difference) of RAECM in the presence and absence of EGTA were determined over time.

\section{Effects of decreased temperature}

To determine the effects of energy depletion, the flux of amine-, carboxylate-, or non-modified quantum dots across RAECM was measured at $4{ }^{\circ} \mathrm{C}$ (and $37^{\circ} \mathrm{C}$ ) over 6 hours using an apical [quantum dot] of $6.25 \mu \mathrm{g} / \mathrm{mL}$.

\section{Effects of endocytosis inhibitors}

To explore if quantum dot translocation across RAECM involves endocytotic mechanisms, methyl- $\beta$-cyclodextrin, chlorpromazine, and dynasore were used to disrupt lipid raft-mediated endocytosis, ${ }^{30,32,36,37}$ clathrin-mediated endocytosis, ${ }^{30,38}$ and dynamin-dependent endocytosis (including clathrin-mediated and caveolin-mediated endocytosis), ${ }^{30,32,39}$ respectively. Briefly, RAECM were pretreated for 30 minutes with methyl- $\beta$-cyclodextrin $(200 \mu \mathrm{M}$, Sigma), chlorpromazine ( $28 \mu \mathrm{M}$, Sigma), or dynasore ( $80 \mu \mathrm{M}$, Sigma) in both apical and basolateral fluids. RAECM were then exposed apically to amine-, carboxylate-, or nonmodified quantum dots $(6.25 \mu \mathrm{g} / \mathrm{mL})$, and the flux of these quantum dots was assessed as described above. Endocytosis inhibitors were present in both apical and basolateral fluids throughout the duration of the flux experiments. Control monolayers were exposed apically to amine-, carboxylate-, or non-modified quantum dots $(6.25 \mu \mathrm{g} / \mathrm{mL})$ without these inhibitors. To determine if dynasore inhibits dynamindependent endocytosis, flux of fluorescein isothiocyanatecholera toxin subunit B (50 $\mu \mathrm{g} / \mathrm{mL}$, Sigma), which involves caveolae-mediated endocytosis, ${ }^{30}$ or Alexa 594-transferrin $(500 \mu \mathrm{g} / \mathrm{mL}$, Invitrogen), which involves clathrin-mediated endocytosis, ${ }^{30}$ was measured in the presence and absence of dynasore. Bioelectric properties (ie, transmonolayer 
resistance, equivalent active ion transport rate, and potential difference) of RAECM in the presence and absence of inhibitors were determined over time.

\section{Immunofluorescence and confocal laser scanning microscopy}

RAECM were exposed apically to $6.25 \mu \mathrm{g} / \mathrm{mL}$ amine-, carboxylate-, or non-modified quantum dots at $37^{\circ} \mathrm{C}$ for 24 hours. RAECM were then washed three times with ice-cold, phosphate-buffered saline (pH 7.2) and fixed with ethanol at $-20^{\circ} \mathrm{C}$ for 5 minutes. Fixed RAECM were incubated with phosphate-buffered saline containing both $5 \%$ bovine serum albumin and $0.2 \% \mathrm{TX}-100$ for 1 hour at room temperature. Rabbit antibody against zonula occludens-1 (Zymed Laboratories, San Francisco, CA), diluted (1:100) in phosphate-buffered saline containing $1 \%$ bovine serum albumin was then incubated with RAECM for 1 hour at $37^{\circ} \mathrm{C}$. Goat antirabbit antibody conjugated with Alexa 488 (Invitrogen) was diluted to 1:100 using 1\% bovine serum albumin in phosphate-buffered saline and used to incubate RAECM at $37^{\circ} \mathrm{C}$ for 1 hour. These RAECM were rinsed with phosphate-buffered saline and mounted on microscope slides with mounting medium containing the nuclear staining dye 4',6-diamidino-2-phenylindole (DAPI) (Vector, Burlingame, CA). RAECM not exposed to quantum dots or those incubated with primary or secondary antibody alone served as negative controls and were similarly processed. Images were acquired with a Leica TCS SP5 confocal fluorescence imaging system (Leica Microsystems, Heidelberg, Germany). The SP5 system was built around a Leica DM6000 CS inverted microscope which is powered by a wideband, fully automated, infrared (680-1080 nm) combined photo-diode pump laser and mode-locked titanium:sapphire laser (Cameleon Ultra II, Coherent, Santa Clara, CA) for multiphoton excitation, and/or by $\mathrm{HeNe}$ and Ar lasers for conventional one photon-excitation confocal microscopy. Alexa 488 and DAPI were excited at 488 and $740 \mathrm{~nm}$, with emission observed at 500-535 nm and 400-460 nm, respectively.

\section{Statistical analysis}

Data are presented as the mean \pm standard error of the mean ( $n=$ total number of RAECM utilized). Student's $t$-tests were performed for comparisons of two group means. One-way analysis of variance followed by post hoc tests based on modified Newman-Keuls procedures was performed to determine statistical significance among means of at least three groups. $P<0.05$ was considered to be statistically significant.
Statistical analyses were carried out using Sigmaplot software (San Jose, CA).

\section{Results}

A summary of zeta potentials of quantum dots utilized in this study measured in water is shown in Table 1. Although the PEG surface of quantum dots are amine-, carboxylate-, or non-modified, all quantum dots exhibited negative zeta potentials, ranging from $-15 \mathrm{mV}$ for amine-modified quantum dots to $-31 \mathrm{mV}$ for non-modified quantum dots.

Figure 1 shows trafficking rates of amine-, carboxylate-, and non-modified quantum dots across RAECM when assessed after 24 hours of exposure at an apical [quantum dot] of $6.25 \mu \mathrm{g} / \mathrm{mL}$. Trafficking rates of these quantum dots do not appear to be affected by surface charge density within the range studied herein. Bioelectric properties (ie, transmonolayer resistance, equivalent active ion transport rate, and potential difference) of RAECM did not change significantly in the apical presence of $6.25 \mu \mathrm{g} / \mathrm{mL}$ quantum dots for 24 hours (data not shown).

Flux of amine-, carboxylate-, and non-modified quantum dots in the absence of EGTA was $0.013 \pm 0.002$, $0.017 \pm 0.002$, and $0.016 \pm 0.004 \mathrm{pg} / \mathrm{cm}^{2} / \mathrm{second}$, respectively, and increased by about $50 \%-130 \%$ in the presence of 2 mM EGTA (Figure 2). Concomitantly, transmonolayer resistance decreased by about $95 \%$ in the presence of $2 \mathrm{mM}$ EGTA (data not shown). After replacing the bathing media with fresh MDS (without EGTA), transmonolayer resistance recovered by $75 \%$ over 12 hours (data not shown).

Flux of amine-, carboxylate-, and non-modified quantum dots at $37^{\circ} \mathrm{C}$ was $0.085 \pm 0.007,0.103 \pm 0.015$, and $0.111 \pm 0.012 \mathrm{pg} / \mathrm{cm}^{2} / \mathrm{second}$, respectively, and all increased by approximately $85 \%$ after 6 hours at $4^{\circ} \mathrm{C}$ (Figure 3 ). Transmonolayer resistance after 6 hours at $4^{\circ} \mathrm{C}$ was about $5 \%$ of the respective control (data not shown). Transmonolayer resistance recovered to approximately $75 \%$ of that before

Table I Surface modification and zeta potential of PEGylated QD (composed of CdSe/ZnS with core size of $5.3 \mathrm{~nm}$ and hydrodynamic size of $25 \mathrm{~nm}$ )

\begin{tabular}{ll}
\hline Surface modification & Zeta potential $(\mathrm{mV})$ in water \\
\hline PEGylated-amine quantum dot & $-15.67 \pm 1.46$ \\
(PEG-NH & ${ }_{2}^{+}$-QD) \\
PEGylated-carboxylate quantum & $-24.47 \pm 4.71$ \\
$\begin{array}{l}\text { dot (PEG-COO-QD) } \\
\text { PEGylated-non-modified quantum }\end{array}$ & $-31.53 \pm 5.78$ \\
dot (PEG-QD) & \\
\hline
\end{tabular}




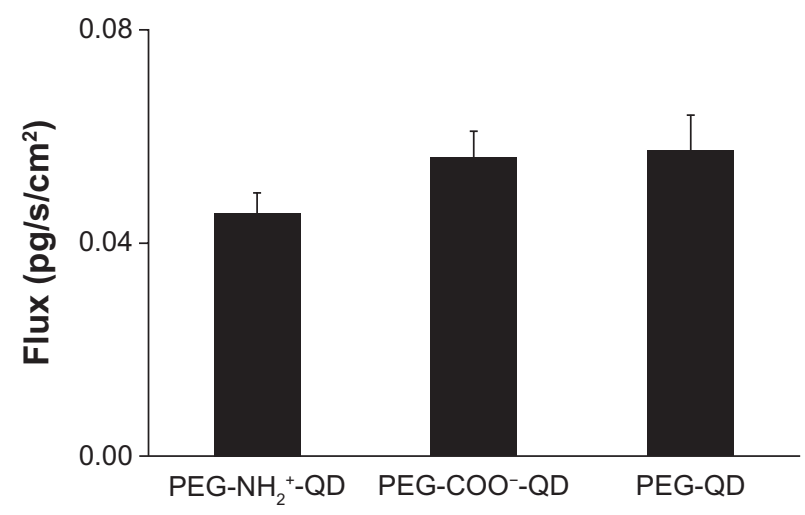

Figure I Fluxes of amine-, carboxylate-, or non-modified quantum dots across rat alveolar epithelial cell monolayers over 24 hours are not significantly different from each other.

Note: Apical [quantum dot] $=6.25 \mu \mathrm{g} / \mathrm{mL}(\mathrm{n}=9)$.

reducing temperature to $4^{\circ} \mathrm{C}$ when temperature was increased to $37^{\circ} \mathrm{C}$ (data not shown).

Figure 4 shows flux of amine-, carboxylate-, and nonmodified quantum dots in the presence or absence of $200 \mu \mathrm{M}$ methyl- $\beta$-cyclodextrin. Flux of amine-, carboxylate-, or non-modified quantum dots in the absence of methyl$\beta$-cyclodextrin was $0.013 \pm 0.003,0.016 \pm 0.002$, and $0.012 \pm 0.003 \mathrm{pg} / \mathrm{cm}^{2} /$ second, respectively, and did not decrease in the presence of methyl- $\beta$-cyclodextrin compared with the respective control. Previously, we showed that flux of cholera toxin subunit B (apical concentration $50 \mu \mathrm{g} / \mathrm{mL}$, used as a positive control) across RAECM decreased by about $75 \%$ in the presence of $200 \mu \mathrm{M}$ methyl- $\beta$-cyclodextrin. ${ }^{30}$ Transmonolayer resistance of RAECM treated with methyl$\beta$-cyclodextrin did not change compared with that of the control (data not shown).

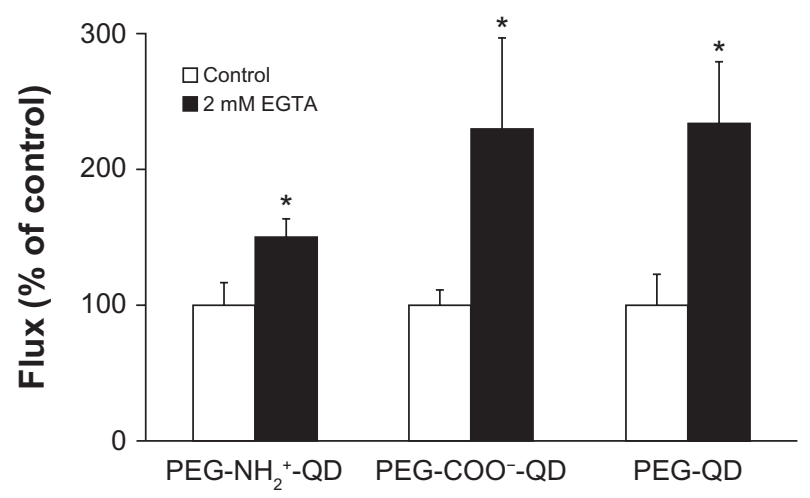

Figure 2 Fluxes of quantum dots across rat alveolar epithelial cell monolayers treated with 2 mM EGTA for 24 hours increased significantly (by about 50\%-130\%) from respective controls. Transmonolayer resistance of rat alveolar epithelial cell monolayers decreased by about $95 \%$ during experiments in the presence of EGTA. Notes: Apical [quantum] $=6.25 \mu \mathrm{g} / \mathrm{mL}$. *Significantly increased compared with control $(n=6)$

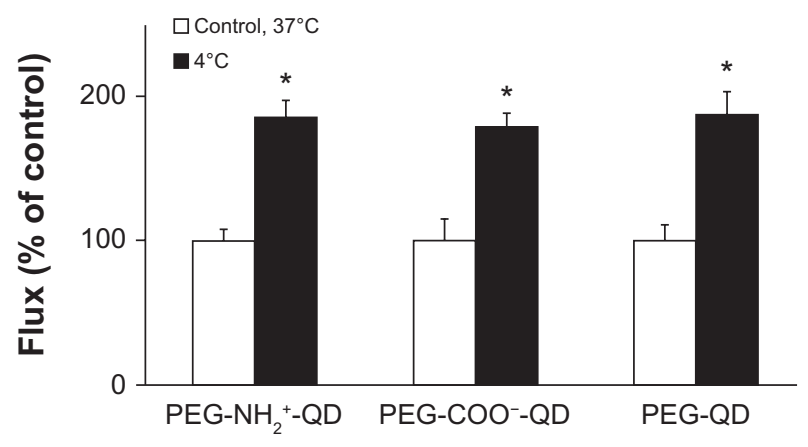

Figure 3 Fluxes of quantum dots across rat alveolar epithelial cell monolayers increased significantly (by about $85 \%$ ) when temperature decreased from $37^{\circ} \mathrm{C}$ to $4^{\circ} \mathrm{C}$. Transmonolayer resistance of rat alveolar epithelial cell monolayers decreased by about $95 \%$ at $4^{\circ} \mathrm{C}$.

Notes: Apical [quantum dot] $=6.25 \mu \mathrm{g} / \mathrm{mL}$. *Significantly increased from control $(n=9)$.

Flux of amine-, carboxylate-, and non-modified quantum dots at baseline was $0.016 \pm 0.002,0.017 \pm 0.001$, and $0.018 \pm 0.001 \mathrm{pg} / \mathrm{cm}^{2} /$ second, respectively, and did not decrease in the presence of $28 \mu \mathrm{M}$ chlorpromazine compared with the respective control (Figure 5). Previously, we showed that flux of transferrin (apical concentration $500 \mu \mathrm{g} / \mathrm{mL}$, used as a positive control) decreased by about $85 \%$ in the presence of chlorpromazine. ${ }^{30}$ Transmonolayer resistance of RAECM treated with chlorpromazine did not change compared with that of the control (data not shown).

Figure 6 shows flux of amine-, carboxylate-, and nonmodified quantum dots in the presence or absence of $80 \mu \mathrm{M}$ dynasore. Flux of amine-, carboxylate-, and non-modified quantum dots in the absence of dynasore was $0.015 \pm 0.002$, $0.022 \pm 0.002$, and $0.027 \pm 0.003 \mathrm{pg} / \mathrm{cm}^{2} / \mathrm{second}$, respectively, and did not decrease in the presence of dynasore compared

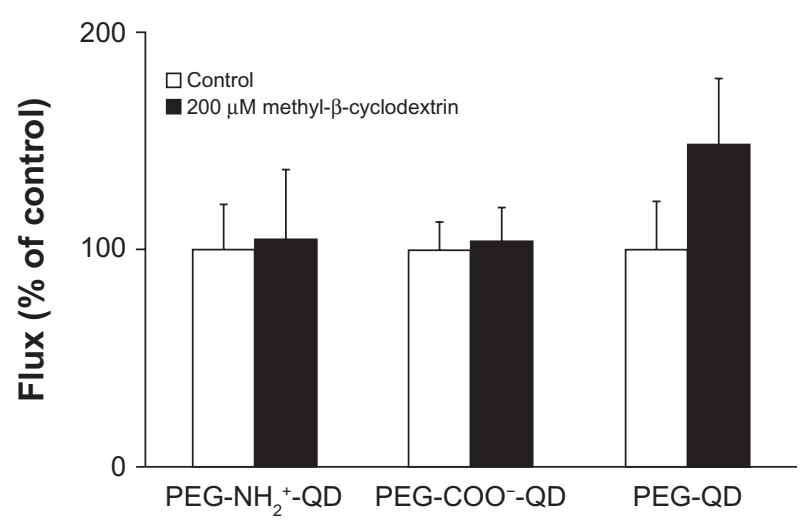

Figure 4 Fluxes of quantum dots $(6.25 \mu \mathrm{g} / \mathrm{mL}$ apical concentration) did not decrease significantly when rat alveolar epithelial cell monolayers were treated with $200 \mu \mathrm{m}$ methyl- $\beta$-cyclodextrin for 24 hours. Transmonolayer resistance was not significantly affected by the presence of methyl- $\beta$-cyclodextrin compared with control $(n=6)$. 


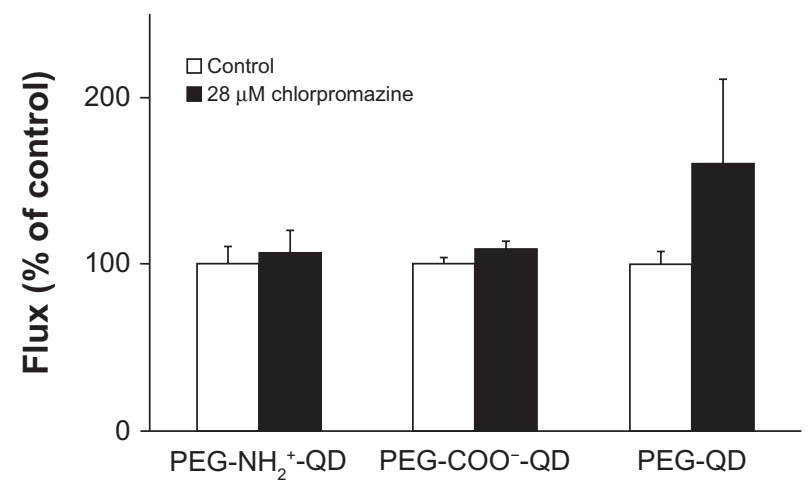

Figure 5 Fluxes of quantum dots $(6.25 \mu \mathrm{g} / \mathrm{mL}$ apical concentration) did not decrease in the presence of $28 \mu \mathrm{M}$ chlorpromazine for 24 hours. Transmonolayer resistance of rat alveolar epithelial cell monolayers after 24 hours of exposure to chlorpromazine was not different from control $(n=6)$.

with the respective control. Flux of cholera toxin subunit B and transferrin (apical concentrations $50 \mu \mathrm{g} / \mathrm{mL}$ and $500 \mu \mathrm{g} / \mathrm{mL}$, respectively, used as positive controls) in the absence of dynasore was $3.22 \pm 0.12$ and $29.54 \pm 7.32 \mathrm{pg} / \mathrm{cm}^{2} / \mathrm{second}$, respectively, and decreased by about $85 \%$ and $72 \%$, respectively, in the presence of dynasore after 24 hours (data not shown). Transmonolayer resistance of RAECM treated with dynasore increased by approximately $30 \%$ (data not shown).

Confocal photomicrographs (Z-max) of RAECM after apical exposure to $6.25 \mu \mathrm{g} / \mathrm{mL}$ amine-modified quantum dots for 24 hours are shown in Figure 7. Quantum dots are seen predominantly in the cytosol, with no apparent localization at cell-cell borders (ie, paracellular pathways). Similar observations were noted with carboxylate- and non-modified quantum dots (data not shown).

\section{Discussion}

This study demonstrates that apical exposure of RAECM to PEGylated quantum dots with amine-, carboxylate-, or non-modified surfaces for 24 hours does not affect alveolar

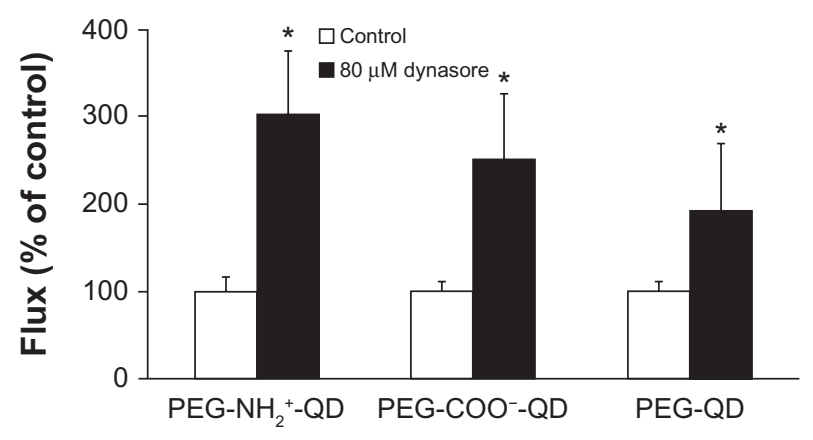

Figure 6 Fluxes of quantum dots $(6.25 \mu \mathrm{g} / \mathrm{mL}$ apical concentration) did not decrease in the presence of $80 \mu \mathrm{M}$ dynasore for 24 hours. Transmonolayer resistance of rat alveolar epithelial cell monolayers was increased by about 30\% after 24 hours of exposure to dynasore compared with control.

Note: *Significantly increased from control $(n=6)$.

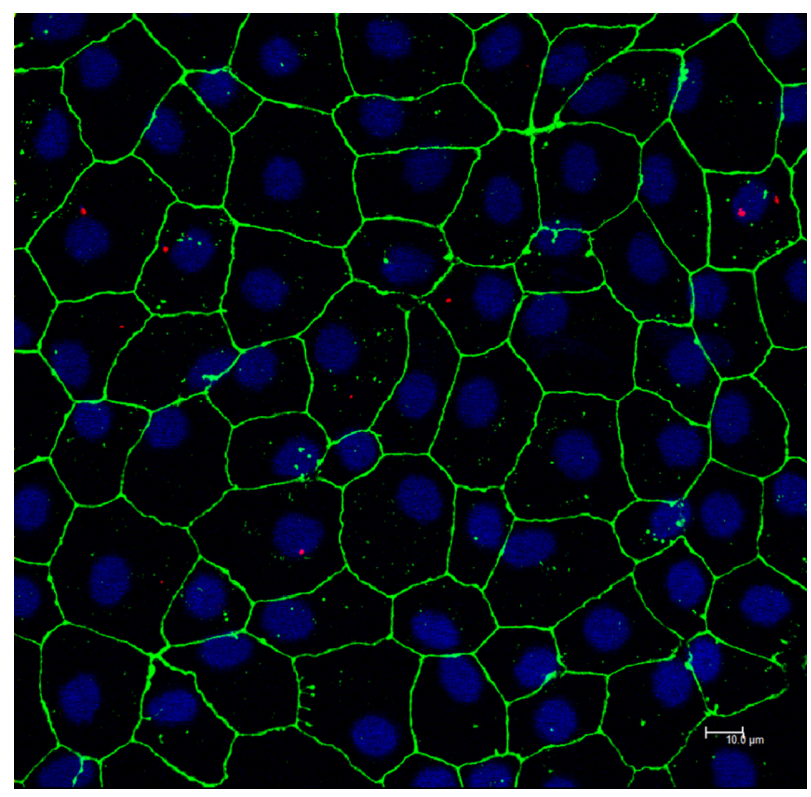

Figure 7 Confocal photomicrograph showing amine-modified PEGylated quantum dots (red) internalized into alveolar epithelial cells following 24 hours of apical exposure to $6.25 \mu \mathrm{g} / \mathrm{mL}$ quantum dots. Zonula occludens-I is shown in green and nuclei are shown in blue.

epithelial barrier properties. Quantum dot translocation across RAECM via transcellular pathways does not appear to require caveolin-, clathrin-, or dynamin-dependent pathways, although quantum dot traffic via paracellular pathways may account (at least in part) for the observed fluxes.

We have previously reported that cationic polystyrene nanoparticles (amidine-modified, zeta potential about $71 \mathrm{mV}$ ) translocate across RAECM 20-40 times faster than anionic polystyrene nanoparticles (carboxylatemodified, zeta potential of about $-45 \mathrm{mV}) .{ }^{30,31}$ Although the range of surface charge of the amine-, carboxylate-, and non-modified PEGylated quantum dots was much less, no effect of surface charge on quantum dot flux across RAECM was seen.

No detectable translocation of quantum dots with nonmodified, amine-modified, or carboxylate-modified surfaces ([apical quantum dot $]=25 \mathrm{nM}$ ) across RAECM over 24 hours was reported by Geys et al, ${ }^{40}$ while significant increases in transmonolayer resistance were observed. The quantum dots used by Geys et $\mathrm{al}^{40}$ were not PEGylated, although their hydrodynamic size and surface charge were similar to our quantum dots. The major difference between the studies is that measurable fluxes were noted for PEGylated quantum dots (our study) versus none for non-PEGylated quantum dots, ${ }^{40}$ likely due to differences in interactions between RAECM and differently coated quantum dots. Greater internalization of carboxylate-coated quantum dots compared 
with that of PEG-coated or PEG-amine-coated quantum dots has been reported for human epidermal keratinocytes. ${ }^{41}$

Although treatment of epithelial cells with EGTA (a calcium chelator) increases paracellular permeability to small solutes, ${ }^{42-45}$ it is unknown if nanoparticles traverse normal and/or EGTA-disrupted tight junctions. In this study, trafficking rates across RAECM of all three quantum dots with different surface modifications increased in the presence of $2 \mathrm{mM}$ EGTA, indicating that these quantum dots traverse RAECM via tight junctional pathways following EGTA treatment. In contrast, Yacobi et $\mathrm{al}^{30}$ concluded that translocation of amidinated (20 and $120 \mathrm{~nm}$ ) or carboxylated (20 and $100 \mathrm{~nm}$ ) polystyrene nanoparticles across RAECM does not take place via paracellular pathways. Trafficking of small hydrophilic solutes (up to $10 \mathrm{~nm}$ ) across epithelial barriers can occur via paracellular pathways, ${ }^{46,47}$ consistent with the small core size of the quantum dots utilized in this study (about $5 \mathrm{~nm}$ ).

Quantum dot trafficking increased across RAECM when temperature was lowered from $37^{\circ} \mathrm{C}$ to $4^{\circ} \mathrm{C}$. At lower temperature, energy-dependent mechanism(s) that may be involved in translocation of quantum dots transcellularly across RAECM will decrease or stop. However, when temperature was decreased to $4^{\circ} \mathrm{C}$, transmonolayer resistance of RAECM decreased by about $90 \%$, suggesting that trafficking of quantum dots is taking place primarily via paracellular pathways at low temperature.

Glycolipid rafts are detergent-insoluble, low-density membrane fractions that are rich in cholesterol and sphingolipids. ${ }^{48}$ Methyl- $\beta$-cyclodextrin extracts cholesterol from plasma membranes and thereby inhibits lipid raft-mediated endocytosis (including caveolin-mediated endocytosis, CLIC/GEEC endocytosis, arf 6-mediated endocytosis, flotillin-mediated endocytosis, and macropinocytosis). ${ }^{37,38}$ We previously reported that $200 \mu \mathrm{M}$ methyl- $\beta$-cyclodextrin markedly decreases flux of cholera toxin subunit B, a positive control for lipid raft-mediated transcytosis across RAECM..$^{30}$ In the present study, flux of quantum dots observed in the presence of $200 \mu \mathrm{M}$ methyl- $\beta$-cyclodextrin did not decrease, suggesting that translocation of quantum dots across RAECM is not taking place via lipid raft-mediated endocytosis. We have reported that translocation of polystyrene nanoparticles across RAECM and Madin Darby canine kidney type II cell monolayers (MDCK-II) was not decreased in the presence of 10-200 $\mu \mathrm{M}$ methyl- $\beta$-cyclodextrin..$^{30,32}$

Clathrin is composed of three light and three heavy chains that form a triskelion. Assembly of the triskelion leads to formation of a net-like basket (clathrin-coated pit) at the cell plasma membrane. Involvement of clathrin-mediated endocytosis in uptake/translocation of various nanoparticles in cells and tissues, eg, amidine-modified polystyrene nanoparticles in MDCK-II, ${ }^{32}$ PEGylated D,L-polylactide (PLA) (PEG-PLA) nanoparticles into HeLa cells ${ }^{49}$ and fullerenic nanoparticles into rat fibroblasts and rat hepatoma cells, ${ }^{50}$ has been reported. Chlorpromazine and other inhibitors of clathrin-mediated endocytosis cause clathrin and AP-2 adaptor protein to relocate to multivesicular bodies and as a result inhibit clathrin-mediated endocytosis. ${ }^{51}$ We reported previously that transferrin utilizes clathrin-mediated endocytosis across RAECM which was inhibited by $28 \mu \mathrm{m}$ chlorpromazine. ${ }^{30}$ However, treatment of RAECM with $28 \mu \mathrm{M}$ chlorpromazine in our current study did not decrease trafficking rates of any quantum dots utilized herein. It has been reported that a charge-dependent clathrin-mediated mechanism appears to be responsible for uptake of positively (but not negatively) charged PEG-PLA nanoparticles into HeLa and MDCK-II cells. ${ }^{49,52}$ In this regard, we recently reported that trafficking of positively (but not negatively) charged polystyrene nanoparticles across MDCK-II is clathrin-mediated. ${ }^{32}$

Dynamin, the membrane scission protein, is a large GTPase which forms a helical polymer around the neck of newly-formed cell plasma membrane invaginations and, upon GTP hydrolysis, mediates the fission of the vesicle from the plasma membrane. Dynamin is essential for caveolin-coated and clathrin-coated vesicle formation and appears to play a role in lipid raft-mediated processes as well. Dynasore, a small, cell-permeable molecule, reversibly inhibits the GTPase activity of dynamin-1 or dynamin-2 at the cell plasma membrane and rapidly blocks vehicle formation. ${ }^{53}$ Our data showing that trafficking rates of quantum dots did not decrease in the presence of $80 \mu \mathrm{M}$ dynasore across RAECM are consistent with the lack of effect of inhibition of endocytosis involving clathrin or lipid rafts (including caveolin). Increased trafficking of quantum dots could be due to upregulation of other translocation pathways (although unlikely to include paracellular pathways with increased transmonolayer resistance) in the presence of dynasore. We reported recently that dynasore has no effect on trafficking rates of polystyrene nanoparticles (20 or 100/120 nm; amidine-modified or carboxylate-modified) across RAECM. ${ }^{30}$ On the other hand, $80 \mu \mathrm{M}$ dynasore inhibited uptake of positively charged $100 \mathrm{~nm}$ polystyrene nanoparticles in HeLa cells by two-fold compared with that of negatively charged polystyrene nanoparticles of comparable size. ${ }^{54}$

Phagocytosis is prevalent in macrophages and dendritic cells, although it can be induced in most cells by expression 
of requisite receptors. ${ }^{55}$ Phagocytosis has also been reported for ATI and ATII cells. ${ }^{56}$ Internalization of large particles and microorganisms, typically greater than $0.5 \mu \mathrm{m}$, is known to occur via phagocytosis, ${ }^{37}$ but it is unlikely that PEGylated quantum dots (core size $5.3 \mathrm{~nm}$, hydrodynamic size $25 \mathrm{~nm}$ ) are significantly phagocytosed.

In summary, we have shown that translocation of amine-, carboxylate-, and non-modified PEGylated quantum dots across RAECM occurs both transcellularly (not involving major endocytic pathways) and paracellularly. Compared with trafficking of polystyrene nanoparticles across RAECM and MDCK-II, nanoparticle interactions with epithelial barriers appear to be both cell type-specific and dependent on nanoparticle physicochemical properties (eg, size, surface charge, and composition).

\section{Acknowledgments}

This work was supported in part by the Hastings Foundation, Whittier Foundation, and research grants (EY011386, EY017293, EY016985, ES017034, ES018782, HL038578, HL038621, HL062569, and HL089445) from the National Institutes of Health. Dr Crandall is Hastings Professor and Norris Chair of Medicine. Dr Borok is Edgington Chair in Medicine.

\section{Disclosure}

The authors report no conflicts of interest in this work.

\section{References}

1. Kim YH, Fazlollahi F, Kennedy IM, et al. Alveolar epithelial cell injury due to zinc oxide nanoparticle exposure. Am J Respir Crit Care Med. 2010;182(11):1398-1409.

2. Xia T, Zhao Y, Sager T, et al. Decreased dissolution of $\mathrm{ZnO}$ by iron doping yields nanoparticles with reduced toxicity in the rodent lung and zebrafish embryos. ACS Nano. 2011;5(2):1223-1235.

3. Wang H, Wang S, Su H, et al. A supramolecular approach for preparation of size-controlled nanoparticles. Angew Chem Int Ed Engl. 2009;48(24):4344-4348.

4. De Jong WH, Borm PJ. Drug delivery and nanoparticles: applications and hazards. Int J Nanomedicine. 2008;3(2):133-149.

5. Haefeli-Bleuer B, Weibel ER. Morphometry of the human pulmonary acinus. Anat Rec. 1988;220(4):401-414.

6. Crandall ED, Matthay MA. Alveolar epithelial transport. Basic science to clinical medicine. Am J Respir Crit Care Med. 2001;163(4): 1021-1029.

7. Cheek JM, Evans MJ, Crandall ED. Type I cell-like morphology in tight alveolar epithelial monolayers. Exp Cell Res. 1989;184(2):375-387.

8. Cheek JM, Kim KJ, Crandall ED. Tight monolayers of rat alveolar epithelial cells: bioelectric properties and active sodium transport. Am J Physiol. 1989;256(3 Pt 1):C688-C693.

9. Danto SI, Zabski SM, Crandall ED. Reactivity of alveolar epithelial cells in primary culture with type I cell monoclonal antibodies. Am J Respir Cell Mol Biol. 1992;6(3):296-306.

10. Schipper ML, Cheng Z, Lee SW, et al. microPET-based biodistribution of quantum dots in living mice. J Nucl Med. 2007;48(9):1511-1518.
11. Qian J, Yong KT, Roy I, et al. Imaging pancreatic cancer using surface-functionalized quantum dots. J Phys Chem B. 2007;111(25): 6969-6972.

12. Walther C, Meyer K, Rennert R, Neundorf I. Quantum dot-carrier peptide conjugates suitable for imaging and delivery applications. Bioconjug Chem. 2008;19(12):2346-2356.

13. Chakravarthy KV, Davidson BA, Helinski JD, et al. Doxorubicinconjugated quantum dots to target alveolar macrophages and inflammation. Nanomedicine. 2011;7(1):88-96.

14. Morosini V, Bastogne T, Frochot C, et al. Quantum dot-folic acid conjugates as potential photosensitizers in photodynamic therapy of cancer. Photochem Photobiol Sci. 2011;10(5):842-851.

15. Wang L, Yang W, Read P, Larner J, Sheng K. Tumor cell apoptosis induced by nanoparticle conjugate in combination with radiation therapy. Nanotechnology. 2010;21(47):475103-475110.

16. Bottrill M, Green M. Some aspects of quantum dot toxicity. Chem Commun (Camb). 2011;47(25):7039-7050.

17. Geys J, Nemmar A, Verbeken E, et al. Acute toxicity and prothrombotic effects of quantum dots: impact of surface charge. Environ Health Perspect. 2008;116(12):1607-1613.

18. Ghasemi Y, Peymani P, Afifi S. Quantum dot: magic nanoparticle for imaging, detection and targeting. Acta Biomed. 2009;80(2): 156-165.

19. Daou TJ, Li L, Reiss P, Josserand V, Texier I. Effect of poly(ethylene glycol) length on the in vivo behavior of coated quantum dots. Langmuir. 2009;25(5):3040-3044.

20. Erogbogbo F, Yong KT, Hu R, et al. Biocompatible magnetofluorescent probes: luminescent silicon quantum dots coupled with superparamagnetic iron(III) oxide. ACS Nano. 2010;4(9):5131-5138.

21. Ma N, Marshall AF, Gambhir SS, Rao J. Facile synthesis, silanization, and biodistribution of biocompatible quantum dots. Small. 2010;6(14): $1520-1528$.

22. Mohs AM, Duan H, Kairdolf BA, Smith AM, Nie S. Proton-resistant quantum dots: stability in gastrointestinal fluids and implications for oral delivery of nanoparticle agents. Nano Res. 2009;2(6):500-508.

23. Chu M, Wu F, Zhang Q, et al. A novel method for preparing quantum dot nanospheres with narrow size distribution. Nanoscale. 2010;2(4):542-547.

24. Bailon P, Won CY. PEG-modified biopharmaceuticals. Expert Opin Drug Deliv. 2009;6(1):1-16.

25. Laia WC, Liau WB. Thermo-oxidative degradation of poly(ethylene glycol)/poly(L-lactic acid) blends. Polymer. 2003;44:8103-8109.

26. Vonarbourg A, Passirani C, Saulnier P, Benoit JP. Parameters influencing the stealthiness of colloidal drug delivery systems. Biomaterials. 2006;27(24):4356-4373.

27. Kah JC, Wong KY, Neoh KG, et al. Critical parameters in the pegylation of gold nanoshells for biomedical applications: an in vitro macrophage study. J Drug Target. 2009;17(3):181-193.

28. Niidome T, Yamagata M, Okamoto Y, et al. PEG-modified gold nanorods with a stealth character for in vivo applications. J Control Release. 2006;114(3):343-347.

29. Schipper ML, Iyer G, Koh AL, et al. Particle size, surface coating, and PEGylation influence the biodistribution of quantum dots in living mice. Small. 2009;5(1):126-134.

30. Yacobi NR, Malmstadt N, Fazlollahi F, et al. Mechanisms of alveolar epithelial translocation of a defined population of nanoparticles. Am J Respir Cell Mol Biol. 2010;42(5):604-614.

31. Yacobi NR, Demaio L, Xie J, et al. Polystyrene nanoparticle trafficking across alveolar epithelium. Nanomedicine. 2008;4(2):139-145.

32. Fazlollahi F, Angelow S, Yacobi NR, et al. Polystyrene nanoparticle trafficking across MDCK-II. Nanomedicine. 2011;7(5):588-594.

33. Aillon KL, Xie Y, El-Gendy N, Berkland CJ, Forrest ML. Effects of nanomaterial physicochemical properties on in vivo toxicity. Adv Drug Deliv Rev. 2009;61(6):457-466.

34. Borok Z, Danto SI, Zabski SM, Crandall ED. Defined medium for primary culture de novo of adult rat alveolar epithelial cells. In Vitro Cell Dev Biol Anim. 1994;30A(2):99-104. 
35. Borok Z, Hami A, Danto SI, Zabski SM, Crandall ED. Rat serum inhibits progression of alveolar epithelial cells toward the type I cell phenotype in vitro. Am J Respir Cell Mol Biol. 1995;12(1):50-55.

36. Parton RG, Richards AA. Lipid rafts and caveolae as portals for endocytosis: new insights and common mechanisms. Traffic. 2003; 4(11):724-738.

37. Doherty GJ, McMahon HT. Mechanisms of endocytosis. Annu Rev Biochem. 2009;78:857-902.

38. Ivanov AI. Pharmacological inhibition of endocytic pathways: is it specific enough to be useful? Methods Mol Biol. 2008;440:15-33.

39. Kirchhausen T, Macia E, Pelish HE. Use of dynasore, the small molecule inhibitor of dynamin, in the regulation of endocytosis. Methods Enzymol. 2008;438:77-93.

40. Geys J, De Vos R, Nemery B, Hoet PH. In vitro translocation of quantum dots and influence of oxidative stress. Am J Physiol Lung Cell Mol Physiol. 2009;297(5):L903-L911.

41. Zhang LW, Monteiro-Riviere NA. Mechanisms of quantum dot nanoparticle cellular uptake. Toxicol Sci. 2009;110(1):138-155.

42. Collares-Buzato CB, McEwan GT, Jepson MA, Simmons NL, Hirst BH. Paracellular barrier and junctional protein distribution depend on basolateral extracellular $\mathrm{Ca}^{2+}$ in cultured epithelia. Biochim Biophys Acta. 1994;1222(2):147-158.

43. Mounier J, Vasselon T, Hellio R, Lesourd M, Sansonetti PJ. Shigella flexneri enters human colonic Caco-2 epithelial cells through the basolateral pole. Infect Immun. 1992;60(1):237-248.

44. Knipp GT, Ho NF, Barsuhn CL, Borchardt RT. Paracellular diffusion in Caco-2 cell monolayers: effect of perturbation on the transport of hydrophilic compounds that vary in charge and size. J Pharm Sci. 1997;86(10):1105-1110.

45. Sergent T, Parys M, Garsou S, Pussemier L, Schneider YJ, Larondelle Y. Deoxynivalenol transport across human intestinal Caco-2 cells and its effects on cellular metabolism at realistic intestinal concentrations. Toxicol Lett. 2006;164(2):167-176.
46. Kim KJ, Crandall ED. Heteropore populations of bullfrog alveolar epithelium. J Appl Physiol. 1983;54(1):140-146.

47. Matsukawa Y, Lee VH, Crandall ED, Kim KJ. Size-dependent dextran transport across rat alveolar epithelial cell monolayers. J Pharm Sci. 1997;86(3):305-309.

48. Nabi IR, Le PU. Caveolae/raft-dependent endocytosis. J Cell Biol. 2003;161(4):673-677.

49. Harush-Frenkel O, Debotton N, Benita S, Altschuler Y. Targeting of nanoparticles to the clathrin-mediated endocytic pathway. Biochem Biophys Res Commun. 2007;353(1):26-32.

50. Li W CC, Ye C, Wei T, et al. The translocation of fullerenic nanoparticles into lysosome via the pathway of clathrin-mediated endocytosis. Nanotechnology. 2008;19(14):145102-145114.

51. Wang LH, Rothberg KG, Anderson RG. Mis-assembly of clathrin lattices on endosomes reveals a regulatory switch for coated pit formation. J Cell Biol. 1993;123(5):1107-1117.

52. Harush-Frenkel O, Rozentur E, Benita S, Altschuler Y. Surface charge of nanoparticles determines their endocytic and transcytotic pathway in polarized MDCK cells. Biomacromolecules. 2008;9(2): 435-443.

53. Macia E, Ehrlich M, Massol R, Boucrot E, Brunner C, Kirchhausen T. Dynasore, a cell-permeable inhibitor of dynamin. Dev Cell. 2006;10(6): 839-850.

54. Dausend J, Musyanovych A, Dass M, et al. Uptake mechanism of oppositely charged fluorescent nanoparticles in HeLa cells. Macromol Biosci. 2008;8(12):1135-1143.

55. Qualmann B, Mellor H. Regulation of endocytic traffic by Rho GTPases. Biochem J. 2003;371(Pt 2):233-241.

56. Corrin B. Phagocytic potential of pulmonary alveolar epithelium with particular reference to surfactant metabolism. Thorax. 1970;25(1): $110-115$.
International Journal of Nanomedicine

\section{Publish your work in this journal}

The International Journal of Nanomedicine is an international, peerreviewed journal focusing on the application of nanotechnology in diagnostics, therapeutics, and drug delivery systems throughout the biomedical field. This journal is indexed on PubMed Central, MedLine, CAS, SciSearch $₫$, Current Contents $₫ /$ Clinical Medicine,

\section{Dovepress}

Journal Citation Reports/Science Edition, EMBase, Scopus and the Elsevier Bibliographic databases. The manuscript management system is completely online and includes a very quick and fair peer-review system, which is all easy to use. Visit http://www.dovepress.com/ testimonials.php to read real quotes from published authors. 